\title{
Metformin Prevents the Increase of Nitric Oxide and Lipid Peroxidation Induced By Dehydroepiandrosterone in Early Pregnant Mice
}

\author{
Carolina G. Luchetti ${ }^{1, *}$, Dante A. Paz ${ }^{2}$ and Alicia B. Motta ${ }^{3}$ \\ ${ }^{1}$ Laboratorio de Biotecnología Animal, Facultad de Agronomía, Universidad de Buenos Aires- CONICET, Argentina \\ ${ }^{2}$ Departamento de Biodiversidad y Biología Experimental, Facultad de Ciencias Exactas y Naturales, Universidad de \\ Buenos Aires - IFIBYNE-CONICET, Argentina \\ ${ }^{3}$ Laboratorio de Fisiopatología Ovárica, Centro de Estudios Farmacológicos y Botánicos (CEFYBO) CONICET - \\ Departamento de Farmacología, Facultad de Medicina, Universidad de Buenos Aires, Argentina
}

\begin{abstract}
The aim of this work was to study the effects of dehydroepiandrosterone (DHEA) and metformin (M) on nitric oxide (NO) system and oxidative stress in embryo implantation sites of early pregnant mice. The biguanide $\mathrm{M}$ is used for treating polycystic ovary syndrome but its complete mechanism of action remains unknown. Nitric oxide (NO) has important protective roles during pregnancy, keeping uterine relaxation and vascular function. However, its overproduction leads to nitrative stress by producing reactive nitrogen species. Here we measured NO content by Griess method and the localization of inducible and endothelial nitric oxide synthase (iNOS and eNOS) by immunohistochemistry in implantation sites. Also we measured lipid peroxidation by TBA-RS, glutathion by Ellman's reaction and antioxidant enzymes by enzymatic kinetics in uterine homogenates. We found that the expression of both iNOS and eNOS and the NO content were increased with DHEA ( $\mathrm{p}<0.001$ for all) and restored to control levels with DHEA+M. Oxidative stress: DHEA increased lipid peroxidation $(\mathrm{p}<0.01)$ and glutathione $(\mathrm{GSH}, \mathrm{p}<0.01)$. With DHEA+M lipid peroxidation was restored to control levels. The activities of the antioxidant enzymes superoxide dismutase and catalase were not modified. We conclude that hyperandrogenization with DHEA enhances the NO system and lipid peroxidation in implantation sites of early pregnant mice and that $\mathrm{M}$ treatment prevents these effects.
\end{abstract}

Keywords: DHEA, metformin, nitric oxide, oxidative stress, polycystic ovary syndrome, pregnancy.

\section{INTRODUCTION}

Nitric oxide (NO) is an essential metabolite involved in vascular function and in numerous physiological processes that maintain homeostasis in mammals. It is a vasodilator agent and it has a biological role to modulate local blood flow and platelet function [1-4]. The production of NO is due to three isoforms of the NO synthase. In healthy vessels endothelial NOS (eNOS) and neuronal NOS (nNOS) constitutively expressed, Ca-dependent enzymes. On the other hand, when the vascular system is diseased and defense mechanisms are activated, the mediators of inflammation induce a NO synthase non-responsive to calcium (iNOS) which produces large quantities of NO in most of the cells of the vessel wall [4-6]. An inadequate production of NO could play a role in many vascular diseases such as hypertension, atherosclerosis, or vascular hyporeactivity associated with septicaemic shock [1].

In pregnancy, NO plays important roles in implantation, decidualization, vasodilatation of decidual, placental and uterine vessels and myometrial relaxation [7]. It has been

*Address correspondence to this author at the Laboratorio de Biotecnología Animal- Facultad de Agronomía- Universidad de Buenos Aires- Av. San Martín 4453- Ciudad de Buenos Aires, Argentina (1417);

Tel/ Fax: (0054) 11-4524-8000; E-mail: caroluchetti@yahoo.com reported that NO participates in vascular invasion by the trophoblast, and it may play a role in maintaining uterine quiescence during pregnancy [8-11]. However, an overproduction of NO can lead to the increase of reactive nitric oxide species (RNOS, more aggressive oxidant species than reactive oxygen species: ROS) [12]. NO could have a dual action (protective or pro-oxidant) in the corpus luteum development $[13,14]$. Peroxynitrite $(\mathrm{ONOO}-/ \mathrm{ONOOH})$, the product of the reaction of $\mathrm{NO}$ with superoxide $\left(\mathrm{O}_{2}{ }^{-}\right)$, leads to nitrative stress, a pro-oxidant and to a pro-inflammatory status, which is associated to pregnancies complicated by preeclampsia, intrauterine growth restriction, pregestational diabetes and miscarriage [13-17]. Besides, it was found that eNOS gene influences the risk of pre-eclampsia and the recurrence of negative pregnancy events [18].

Although NO synthases iNOS and eNOS have been identified in rodent uterus via western blot analysis and immunohistochemistry during implantation and late gestation [19, 20], very few localization and/ or quantification studies of NOS and NO during early pregnancy have been performed.

Dehydroepiandrosterone (DHEA) is the most abundant androgen found in women with polycystic ovary syndrome (PCOS) [21]. This hormone is involved in immune homeostasis and is increased in normal pregnancy contributing to the development of gestation [22]. It has been reported that 
DHEA regulates vascular function, having a protective role [23]. However, abnormally increased DHEA leads to an imbalance in ovarian function and in detrimental effects on endometrial function. This results in low implantation rates and miscarriage [24-27]. Simoncini et al. 2003 have reported that DHEA induces NO synthesis by a direct effect on eNOS [28]. We have previously developed a murine model hyperandrogenized with DHEA which reflects endocrine and immune aspects of women with PCOS during early pregnancy [26].

The insulin-sensitizing drug metformin (M) is widely used in the treatment of type II diabetes mellitus $[29,30]$ and PCOS $[31,32]$. These conditions are accomplished with a decreased antioxidant capacity that could contribute to the known increased risk of cardiovascular diseases as atherosclerosis or hypertension in patients with diabetes and PCOS $[33,34]$. The biguanide $M$ is a non-hormonal treatment that has shown to reduce oxidative stress in numerous systems. Apparently it exerts its antioxidant effects directly scavenging ROS or indirectly modulating the intracellular ROS production [35-40]. Moreover, NO has been proposed as an intermediate of the M action [41]. In women with PCOS, it has been seen that $M$ treatment decreases androgen levels, improves frequency of menstrual cycle and ovulation [4246] and prevents abortions in early pregnant women with PCOS [47-50]. Considering that there are an increasing number of women with PCOS who became pregnant after M treatment it is expected that the use of this drug around and during the time of pregnancy will increase. However, the clinical practice is ahead of the knowledge of the mechanism involved, which remains partially unknown.

In recent works using our DHEA-treated-early pregnancy model we have shown that $M$ prevented some endocrine and immune alterations induced by DHEA: embryo resorption, glucose, progesterone, progesterone-induced blocking factor (PIBF) and cyclooxygenase2 (COX2) in the implantation sites, cytokine production, ovarian oxidative stress and uterine NOS activity [51, 52].

In the present report we focused on determining the localization of iNOS and eNOS, as well as the NO production and oxidative stress at the implantation sites during early pregnancy. We also were interested in knowing the local effects of DHEA and M on these parameters. In this way, we are expanding our previous findings on the mechanisms by which DHEA induces and $M$ prevents embryo resorption on early pregnant $\mathrm{BALB} / \mathrm{c}$ mice.

\section{MATERIALS AND METHODS}

\section{Animals}

All procedures involving animals were conducted in accordance with the Guide for the Care and Use of Laboratory Animals (The National Academies Press, Washington, D.C., 2011 [53]). The studies were approved by the Independent Committee on Ethics in Research of the School of Medicine of the University of Buenos Aires. The mice were housed under controlled temperature $\left(22^{\circ} \mathrm{C}\right)$ and illumination $(14 \mathrm{~h}$ light, 10-h darkness; lights on at 05:00) and allowed free access to Purina Rat Chow and water. A total of 86 virgin female $\mathrm{BALB} / \mathrm{c}$ mice (8-12-week-old) were paired with BALB/c males (8-12-week-old). The animal model used has been previously described [52]. Briefly, the day of appearance of a coital plug was taken as day 0 of pregnancy. Implantation occurs in the morning of the 5th day, therefore, on 6th and 7th days (post-implantation) animals were divided in 4 groups: Control (supplied with vehicles), M (treated orally by canulla with $240 \mathrm{mg} / \mathrm{kg}$ of metformin in $0.1 \mathrm{ml}$ of water), DHEA (injected s.c. with $60 \mathrm{mg} / \mathrm{kg}$ of dehydroepiandrosterone in $0.1 \mathrm{ml}$ of sesame oil) and DHEA+M (treated under the same conditions with DHEA and M). On day 8 of pregnancy (bodyweight $20 \pm 2 \mathrm{~g}$ ), animals were euthanized by cervical dislocation. After embryos were removed, uterine tissues from 14 animals per group were divided as follows: 7 uteri of each group were immediately homogenized in buffer Tris-Base $20 \mathrm{mM}, \mathrm{pH}=7,6$ to determine oxidant-antioxidant parameters (superoxide dismutase and catalase activity, lipid peroxidation, glutathione and nitrites concentration). The remaining 7 uteri were immediately fixed in $4 \%(w / v)$ paraformaldehyde to carry out immunohistochemical determination of eNOS and iNOS.

In order to test any long-term adverse effect of the treatments, 3 additional groups of mice (10 animals each) including Control, $\mathrm{M}$ and DHEA+M, were allowed to proceed to parturition. These animals had a normal pregnancy with normal number and morphology of pups (8-12 pups/litter).

\section{Experimental Procedures}

\section{Immunohistochemical Localization of iNOS and eNOS}

The immunolocalization of iNOS and eNOS was performed on implantation sites. Uterine sections were stained with immunoperoxidase staining kit CSA/ HRP (Dako). Briefly, uterine tissues fixed in $4 \%$ paraformaldehyde were embedded in paraffin wax, consecutively cut $(6-\mu \mathrm{m}$-thick sections) and placed on silanized glass slides (Biobond; British Biocell International, Cardiff). Only sections that passed through the center of the implantation sites were selected.

Then, tissue sections were deparaffinized, rehydrated through a series of graded alcohols and washed in PBS. Endogenous peroxidase activity was blocked with $0.1 \%(\mathrm{v} / \mathrm{v})$ hydrogen peroxide for $50 \mathrm{~min}$. Non-specific binding sites were blocked by treating tissues with TNB blocking reagent (NEN Life Science Products, Boston, MA, USA). Then, sections were incubated overnight at $4^{\circ} \mathrm{C}$ with rabbit polyclonal anti- human eNOS and iNOS antibodies respectively (Cayman Chemical Company, Ann Arbor, MI, USA) diluted 1:200 in blocking buffer. Control sections were processed without primary antibody. Sections were then incubated for 30 min with biotinylated anti-rabbit antibody, washed in PBS and treated with streptavidin-biotin complex for 30 $\min$. The reaction was visualized by diaminobenzidine (DAB staining kit, Dako; Hamburg, Germany) and sections were counterstained with haematoxylin and covered with DPX (Sigma-Aldrich, St Louis, MO, USA).

Immune mark was analyzed using Image-Pro Plus version 4.1 (Media Cybernetics, Silver Spring, MD). It was determined marked area/ total area and expressed as a percentage.

\section{Nitric Oxide Concentration}

Nitrites concentration was determined by the Griess reaction, a colorimetric assay based on the reaction of $\mathrm{NaNO}_{2}$ 
with sulfanilic acid that produces color readable at $540 \mathrm{~nm}$ [54]. Samples were incubated with sulfanilic acid and values were referred to a $\mathrm{NaNO}_{2}$ standard curve. $\mathrm{NO}_{2}$ concentration was expressed as nmol $\mathrm{NO}_{2} / \mathrm{mg}$ protein.

\section{Oxidative Stress-Related Parameters}

Uterine tissues without embryos were homogenized in buffer Tris-Base $20 \mathrm{mM}, \mathrm{pH}=7,6$ with a Teflon-glass homogenizer on ice. The suspension was centrifuged at 9000 $\times g$ for $10 \mathrm{~min}$ at $4^{\circ} \mathrm{C}$. The pellet was discarded and the supernatant was saved and stored at $-20^{\circ} \mathrm{C}$ for the oxidative stress determinations that are described ahead and for the protein content determination by Bradford method.

\section{Superoxide Dismutase (SOD)}

SODs are a group of metalloenzymes that detoxify ROS through the conversion of $\mathrm{O}_{2}{ }^{\circ-}$ to hydrogen peroxide and molecular oxygen. Total SOD activity was assayed by a spectrophotometric method based on the inhibition of a superoxide-induced epinephrine oxidation [55]. Briefly, 30 $\mathrm{mM}$ epinephrine in $0.05 \% \mathrm{v} / \mathrm{v}$ acetic acid was added to 50 $\mathrm{mM}$ glycine buffer $(\mathrm{pH}=10,2)$ with uterine homogenates. SOD activity was measured at $480 \mathrm{~nm}$ for $4 \mathrm{~min}$. One unit (U) is equivalent to the amount of enzyme that inhibited the oxidation of epinephrine by $50 \%$. It was expressed as USOD/ mg protein.

\section{Catalase}

The enzyme catalase promotes the conversion of hydrogen peroxide $\left(\mathrm{H}_{2} \mathrm{O}_{2}\right)$ into water and oxygen $\left(\mathrm{H}_{2} \mathrm{O}+\mathrm{O}_{2}\right)$. The consumption of $\mathrm{H}_{2} \mathrm{O}_{2}$ was monitored by spectrophotometer in a reaction medium consisting of $50 \mathrm{mM}$ phosphate buffer, $\mathrm{pH} 7,2$ and $3 \mathrm{mM} \mathrm{H}_{2} \mathrm{O}_{2}$ every $10 \mathrm{sec}$ during $1 \mathrm{~min}$ at $240 \mathrm{~nm}$ [56]. Results were expressed as nmol catalase/ $\mathrm{mg}$ protein.

\section{Lipid Peroxidation}

The amount of malondialdehyde (MDA), product of the breakdown of polyunsaturated fatty acids, may be taken as an index of peroxidation reaction. The TBA reactive species (TBA-RS) method was previously described [57] and quantifies MDA, that reacts with trichloroacetic acid (TCA) $15 \%$ (w/v)- thiobarbituric acid (TBA) $0.375 \%$ (w/v)- HCI $0.25 \mathrm{M}$, yielding a red compound that absorbs at $535 \mathrm{~nm}$. Homogenates were treated with TCA-TBA- $\mathrm{HCl}$ and heated for $15 \mathrm{~min}$ in water at $100^{\circ} \mathrm{C}$. After cooling, the flocculent precipitate was removed by centrifugation at $1000 \times g$ for $10 \mathrm{~min}$. The absorbance of samples was determined at $535 \mathrm{~nm}$. Results were expressed as nmol MDA/ mg protein.

\section{Glutathione Content}

The GSH assay was previously described [58]. The reduced form of GSH comprises the bulk of cellular protein sulphydryl groups. Thus, measurement of acid-soluble thiol is used for estimation of GSH content in tissue extracts. Briefly, $300 \mu \mathrm{l}$ of uterine homogenates were incubated with buffer Tris $1.75 \mathrm{M}(\mathrm{pH}=7,4)$ containing NADPH and GSH reductase. The reaction involves the enzymatic reduction of the oxidized form (GSSG) to GSH. When Ellman's reagent (a sulphydryl reagent 5, 5-dithiobis-2 nitrobenzoic acid; Sigma-Aldrich, St Louis, MO, USA) is added to the incubation medium, the chromophoric reaction product absorbs at $412 \mathrm{~nm}$ with a linear increase during $6 \mathrm{~min}$; after this, the reaction remains constant. Results were expressed as mmol $\mathrm{GSH} / \mathrm{mg}$ protein.

\section{Statistical Analysis}

Statistical analyses were carried out using the Instat program (GraphPAD software, San Diego, CA, USA). One way ANOVA test was used (Tukey post-test Multiple Comparison that compares all the pairs of columns). A P value $<0.05$ was considered significant. Results are presented as mean \pm SEM.

\section{RESULTS}

\section{Expression of iNOS and eNOS in Implantation Sites}

The immunohistochemical analysis of iNOS and eNOS in implantation sites showed that in Control and DHEA+M these enzymes are expressed in trophoblastic and maternal blood cells (Fig. 1A and $\mathbf{C}$ for iNOS, $\mathbf{2 A}$ and $\mathbf{C}$, for eNOS: $\mathrm{tr}, \mathrm{bc})$. The expression in $\mathrm{M}$ treated mice showed an appearance similar to Control (picture not shown). In DHEA treated mice these proteins showed an increased expression on decidual matrix when compared to Control (Fig. 1B and 2B: md and amd). Quantification of marked area/ total area by Image Pro Plus revealed that DHEA increased the protein expression of iNOS (Fig. 1D, One way ANOVA *** $\mathrm{p}<0.001$ ) and eNOS (Fig. 2D, One way ANOVA $* * *$ $\mathrm{p}<0.001)$. Treatment with metformin $(\mathrm{DHEA}+\mathrm{M})$ partially avoided this increase for iNOS while eNOS expression was significantly lower than Control (Fig. 2D, One way ANOVA $* * * \mathrm{p}<0.001)$.

\section{Nitric Oxide Concentration}

Nitric oxide (NO) concentration in uterine homogenates without embryos was increased by DHEA respect to Control (Fig. 3, One way ANOVA *** $\mathrm{p}<0.001$ ). This increase was avoided by the treatment with metformin (DHEA+M).

\section{Oxidant/ Antioxidant Status}

Four parameters of the oxidant/ antioxidant status were measured in uterine homogenates without embryos: superoxide dismutase and catalase, lipid peroxidation and glutathione. Superoxide dismutase and catalase showed no differences between treatments (Fig. 4A and Fig. 4B respectively, One way ANOVA p>0.05). Lipid peroxidation suffered an increase in hyperandrogenized mice (DHEA) respect to Control (Fig. 4C, One way ANOVA ** p<0.01) and metformin treatment prevented this effect $(\mathrm{DHEA}+\mathrm{M})$. The antioxidant metabolite glutathione was increased both with DHEA and with DHEA+M (Fig. 4D, One way ANOVA ** $\mathrm{p}<0.01)$.

\section{DISCUSSION}

\section{DHEA- Hyperandrogenization}

The present murine model resembles the endocrine and immune profile of early pregnant women with PCOS treated with metformin [51, 52]. High concentrations of DHEA induce a pro-inflammatory environment and triggers the synthesis of nitric oxide (NO) [52,59,60]. Besides, this induces the loss of luteal function and embryo resorption [26,51,61]. The present findings show the increase in NOS expression and in NO production after hyperandrogenization. We propose 


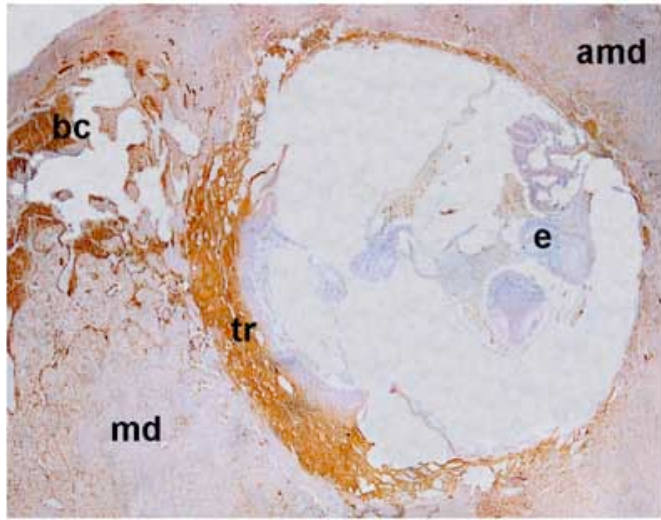

A

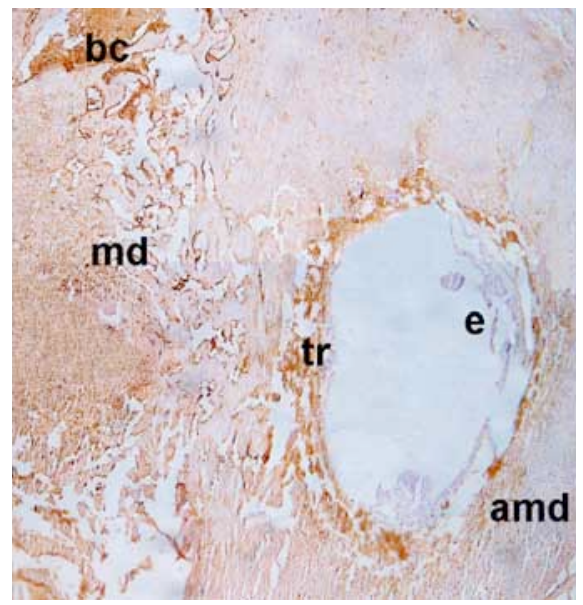

C

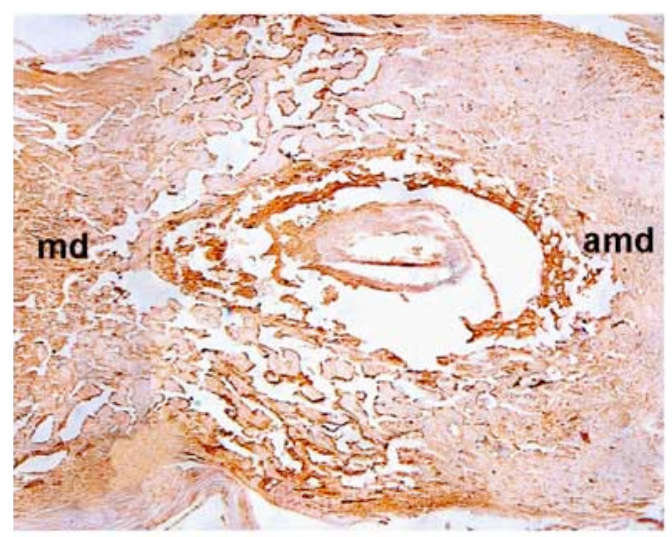

$\mathbf{B}$

iNOS

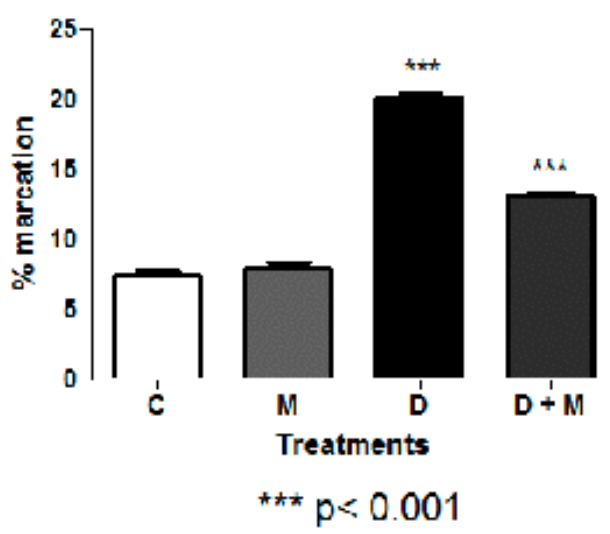

D

Fig. (1). immunolocalization for iNOS in implantation sites from 8 days pregnant mice. Immunohistochemistry was performed in uterine sections incubated with anti-iNOS antibody and stained with an immunoperoxidase staining kit. The intense brown color indicates positive staining. A: Control (40 X). iNOS immunoreactivity is present in trophoblastic (see tr) and in maternal blood cells (see bc). B: DHEA (40 X). The positive staining is extended to the entire decidual matrix (see md and amd). In this slide it is possible to see a remaining trophoblastic tissue that is also positive for iNOS. C: DHEA+M $(40 \mathrm{X})$. The localization of iNOS is similar to Control, but the decidual matrix shows a more intense staining than this group. D: Quantification of marked area / total area by Image Pro Plus. iNOS expression was increased in DHEA treated mice. $M$ treatment partially prevented this effect. Error bars represent the mean \pm SEM, one way ANOVA $* * * p<0.001, \mathrm{~N}=7 /$ group.

e: embryo. tr: trophoblast. md: mesometrial decidua. amd: antimesometrial decidua. bc: maternal blood cells.

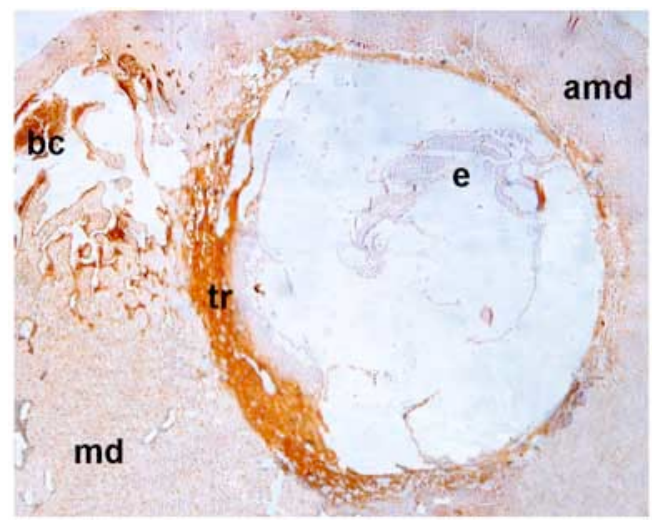

A

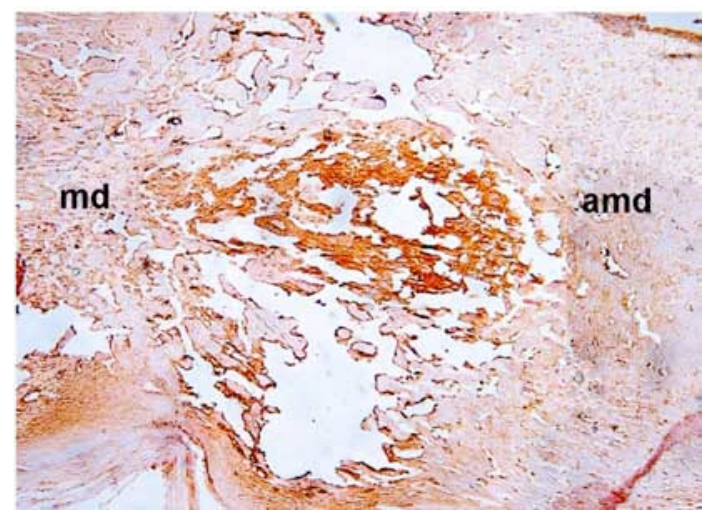

B 


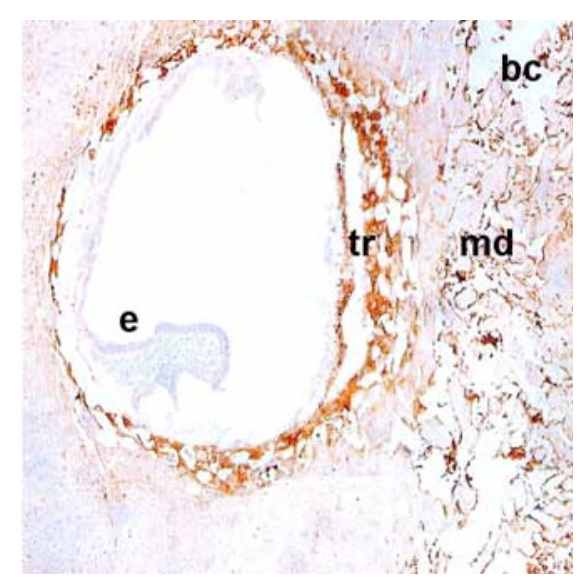

C
eNOS

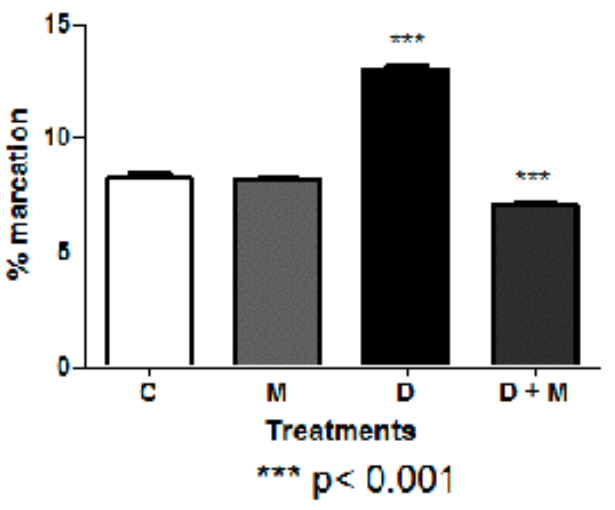

D

Fig. (2). immunolocalization for eNOS in implantation sites from 8 days pregnant mice. Immunohistochemistry was performed in uterine sections incubated with anti-eNOS antibody and stained with an immunoperoxidase staining kit. The intense brown color indicates positive staining. A: Control (40 X). eNOS immunoreactivity is present in the trophoblastic (see tr) and in maternal blood cells (see bc). B: DHEA $(40 \mathrm{X})$. The positive staining is extended to the entire decidual matrix (see md and amd). In this slide it is possible to see a remaining trophoblastic tissue that is also positive for eNOS. C: DHEA+M (40 X). The localization of eNOS is similar to Control. D: Quantification of marked area / total area by Image Pro Plus. eNOS expression was increased in DHEA treated mice. eNOS expression in DHEA+M was significantly lower than in Control. Error bars represent the mean \pm SEM, one way ANOVA *** p<0.001, N=7/group.

e: embryo. tr: trophoblast. md: mesometrial decidua. amd: antimesometrial decidua. bc: maternal blood cells.

NO2

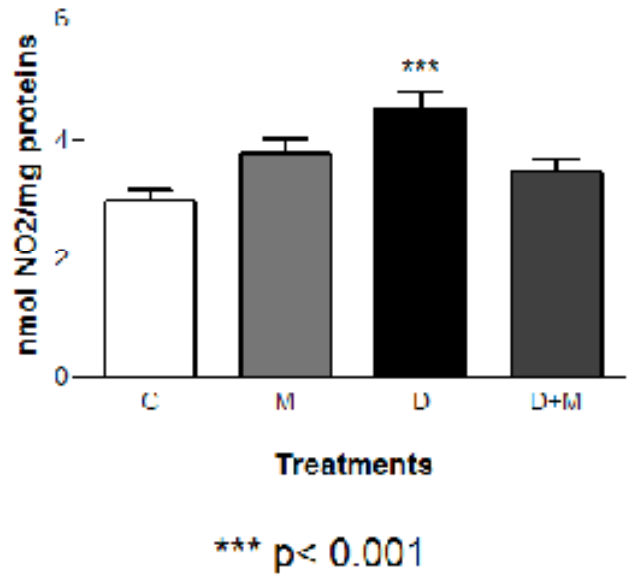

Fig. (3). Nitrites concentration was determined by the colorimetric Griess method in uterine homogenates without embryos from 8 days pregnant mice. The hyperandrogenized group (DHEA) showed a significant increase in nitrites respect to Control that was avoided by the simultaneous treatment with metformin $(\mathrm{DHEA}+\mathrm{M})$. Error bars represent the mean \pm SEM, one way ANOVA $* * * \mathrm{p}<0.001, \mathrm{~N}=7 /$ group.

SOD

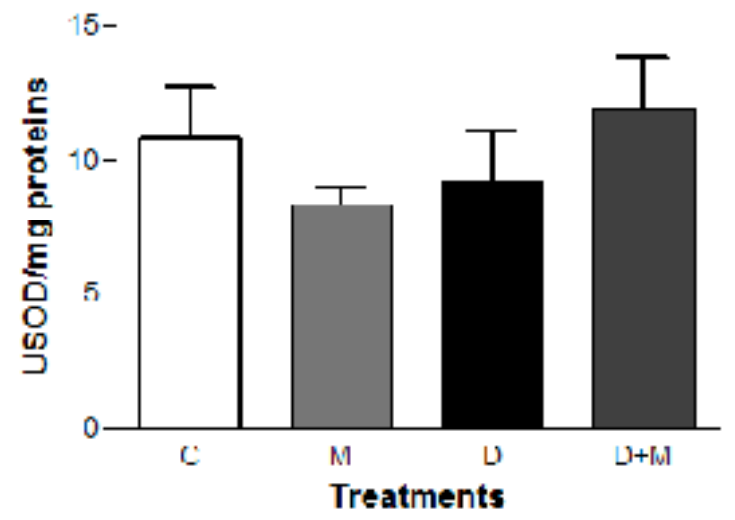

A
Catalase

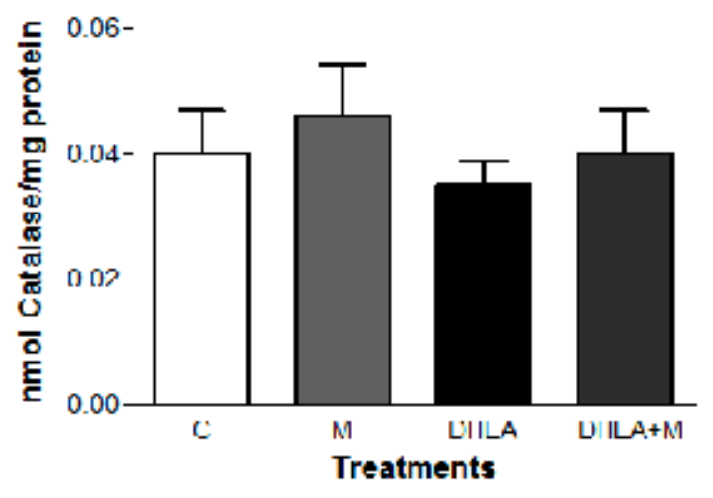

B 


\section{Lipid peroxidation}

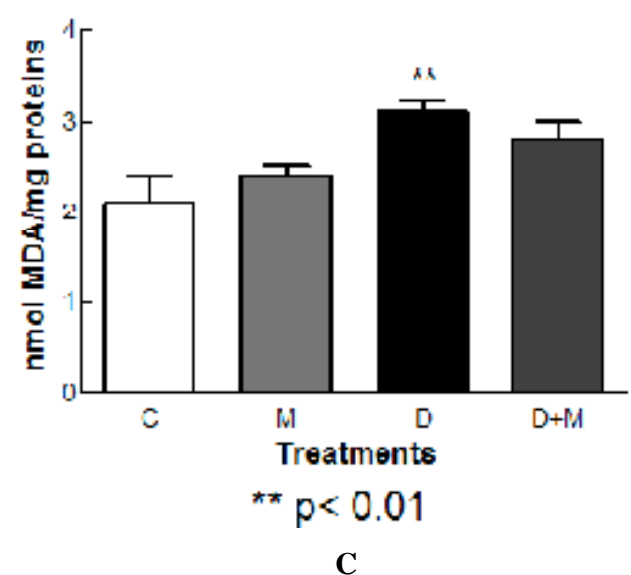

GSH

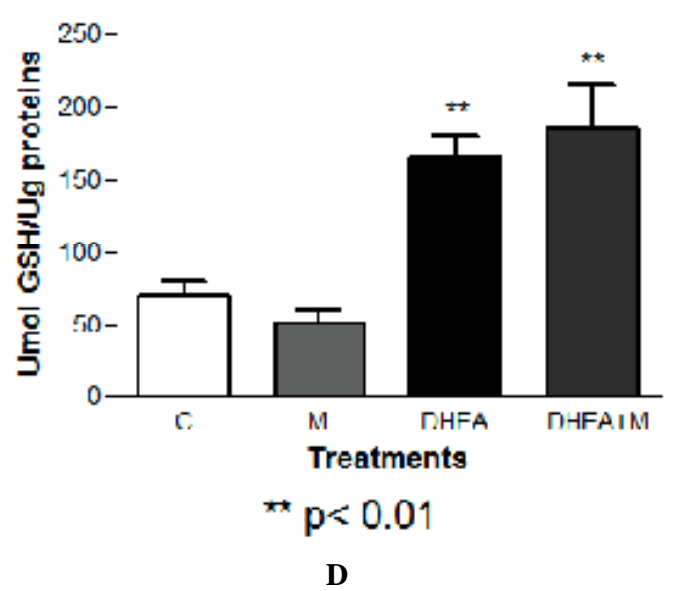

Fig. (4). oxidative stress in uterine homogenates without embryos from 8 days pregnant mice.

A: the concentration of the antioxidant enzyme superoxide dismutase (SOD) was determined by a colorimetric method that measures epinochrome disappearance. This enzyme showed no differences between treatments. Error bars represent the mean \pm SEM, one way ANOVA $\mathrm{p}>0.05, \mathrm{~N}=7 /$ group.

B: the concentration of the antioxidant enzyme catalase was determined by a colorimetric method that measures epinephrine disappearance. This enzyme showed no differences between treatments. Error bars represent the mean \pm SEM, one way ANOVA p >0.05, N=7/group.

C: the product of lipid peroxidation malondialdehyde (MDA) was detected by TBA-RS. Hyperandrogenized mice (DHEA) suffered an increase in lipid peroxidation respect to Control and $\mathrm{M}$ treatment prevented this effect (DHEA+M). Error bars represent the mean \pm SEM, one way ANOVA ** $\mathrm{p}<0.01, \mathrm{~N}=7 /$ group.

D: the concentration of the antioxidant metabolite GSH was measured by a colorimetric method that detects the GSH reductase activity. Hyperandrogenization increased GSH. The treatment with metformin (DHEA+M) showed no differences with DHEA and was different from Control. Error bars represent the mean \pm SEM, one way ANOVA $* * \mathrm{p}<0.01, \mathrm{~N}=7 /$ group.

that NO has an important role in the cascade of events triggered by high concentrations of DHEA that leads to embryo resorption. We base this idea on the increased levels of NO, iNOS and eNOS in DHEA-hyperandrogenized mice, with an increased rate of embryo resorption and on previous reports showing a direct effect of DHEA on NO production modulating iNOS and eNOS expression [28, 51]. In a previous work of our group using the same mouse model of hyperandrogenization with DHEA, we have observed a decrease in NOS activity [51]. The increase in the expression and the decrease in the activity of NOS seem contradictory; nevertheless, a possible explanation could be that NOS is increased by high levels of DHEA leading to an overproduction of NO that could down-regulate the activity of NOS. This mechanism of regulation of $\mathrm{NO}$ has been seen in other experimental models [62, 63].

The increased concentrations of NO are accomplished by oxidative stress in the uterine tissue. This is reflected in the increase in lipid peroxidation, index of the oxidative damage to the tissue. Regarding the antioxidant defenses, the enzymes measured here are not modified by any of the treatments but the antioxidant metabolite GSH is increased by DHEA treatment, possibly as a reaction to the oxidation. The association between elevated NO and oxidative stress agrees with the previous knowledge about the pro-oxidant effect of high levels of NO in corpus luteum development [13, 16-18].

In this study we localized for the first time the enzymes iNOS and eNOS in murine implantation sites during early pregnancy: these enzymes are expressed in the trophoblastic and maternal blood cells. This localization could be ex- plained because of the very dynamic remodeling of maternal vessels in implantation sites during early pregnancy [8-11].

\section{Treatment with Metformin}

In previous reports we have seen that the treatment with metformin prevents most of the effects induced by DHEA in mice having protective effects on ovaries and uterus. [51, 52, 64]. In the present work we demonstrate that $M$ totally prevents the increase in NO induced by DHEA. This prevention is not due to an effect on the NOS activity (as we have seen in a previous work [51]), but to an effect on the NOS expression. Regarding the expression of iNOS, this treatment reverts partially the increase induced by DHEA, whereas with regard to the eNOS $M$ reverts its increase and even we observe a decrease in DHEA+M respect to Control that we cannot explain.

$\mathrm{M}$ is known to have an antioxidant role [35-40]. Our present results are in agreement with this because $M$ prevents the increase in lipid peroxidation induced by DHEA. GSH is also elevated in DHEA+M. The increase in GSH could have a role in the prevention of lipid peroxidation because it is an instantaneous antioxidant defense.

The treatment with metformin seems to be a good option for maintaining pregnancy to term in patients with PCOS. Regulation of nitric oxide by $M$ probably favors the normal vascular function in these patients. It could contribute to decreasing the risk of cardiovascular diseases [33, 34]. Besides, $\mathrm{M}$ is a non-hormonal treatment and did not show to be teratogenic, making it a good choice for patients with PCOS [50, 64]. 
There remain some aspects to be studied, including long time effects of this treatment in pregnancy. It would be interesting to focus on the offspring born under metformin treatment, its glucose metabolism, its endocrine regulation and reproductive performance.

\section{CONCLUSION}

On the basis of the present results, we conclude that DHEA induces and metformin prevents a detrimental increase in NOS and NO and lipid peroxidation in implantation sites during early pregnancy in mice. This work contributes to the knowledge and explanation of the etiology of PCOS during early pregnancy. It investigates the mechanism of action of DHEA, one of the principal androgens present in PCOS, and of metformin, a promising drug for treatment of PCOS. Moreover, this study deepens the knowledge of some important factors that are decisive for pregnancy, like NOSNO system and oxidant/antioxidant balance. These factors contribute to pregnancy success or fail and lead to miscarriage.

\begin{tabular}{|c|c|c|}
\hline \multicolumn{3}{|c|}{ ABBREVIATIONS } \\
\hline $\mathrm{COX} 2$ & $=$ & cyclooxygenase 2 \\
\hline DHEA & $=$ & dehydroepiandrosterone \\
\hline eNOS & $=$ & endothelial nitric oxide synthase \\
\hline $\mathrm{g}$ & $=$ & times gravity \\
\hline GSH & $=$ & Glutathione \\
\hline $\mathrm{h}$ & $=$ & hours \\
\hline HCI & $=$ & hydrochloric acid \\
\hline iNOS & $=$ & inducible nitric oxide synthase \\
\hline $\mathrm{Kg}$ & $=$ & kilograms \\
\hline M & $=$ & metformin \\
\hline MDA & $=$ & malondialdehyde \\
\hline $\mathrm{mg}$ & $=$ & milligrams \\
\hline $\min$ & $=$ & minutes \\
\hline$\mu \mathrm{l}$ & $=$ & microliters \\
\hline $\mathrm{mM}$ & $=$ & millimolar \\
\hline NADPH & $=$ & $\begin{array}{l}\text { Nicotinamide adenine dinucleotide phos- } \\
\text { phate }\end{array}$ \\
\hline $\mathrm{nm}$ & $=$ & nanometers \\
\hline NO & $=$ & Nitric oxide \\
\hline PCOS & $=$ & polycystic ovary syndrome \\
\hline PIBF & $=$ & progesterone-induced blocking factor \\
\hline pmol & $=$ & picomoles \\
\hline RNOS & $=$ & reactive nitric oxide species \\
\hline ROS & $=$ & reactive oxygen species \\
\hline $\mathrm{sc}$ & $=$ & subcutaneously \\
\hline
\end{tabular}

$\begin{array}{lll}\sec & = & \text { seconds } \\ \text { SOD } & = & \text { Superoxide dismutase } \\ \text { TBA } & = & \text { thiobarbituric acid } \\ \mathrm{TCA} & = & \text { trichloroacetic acid } \\ \mathrm{w} / \mathrm{v} & = & \text { weight/volume }\end{array}$

\section{CONFLICT OF INTEREST}

The authors confirm that this article content has no conflicts of interest.

\section{ACKNOWLEDGEMENTS}

Authors would like to thank Federico Pereyra-Bonnet, $\mathrm{PhD}$ and Gustavo Gallardo, MD for their careful reading and invaluable contribution to this work.

\section{REFERENCES}

[1] Schini VB, Vanhoutte PM. Nitric oxide and homeostasis of the smooth vascular muscle. Arch Mal Coeur Vaiss 1993; 86 (1): 83-9.

[2] Star RA. Nitric oxide. Am J Med Sci 1993; 306(5): 348-58.

[3] Palmer RM, Ferrige AG, Moncada S. Nitric oxide release accounts for the biological activity of endothelium-derived relaxing factor Nature 1987; 327(6122): 524-6.

[4] Moncada S, Palmer RM, Higgs EA. The discovery of nitric oxide as the endogenous nitrovasodilator. Hypertension 1988; 12(4): 36572.

[5] Andrew PJ, Mayer B. Enzymatic function of nitric oxide synthases. Cardiovasc Res 1999; 43(3): 521-31.

[6] Ignarro LJ. Endothelium-derived nitric oxide: pharmacology and relationship to the actions of organic nitrate esters. Pharmacol Res 1989; 6(8): 651-9.

[7] Sladek SM, Magness RR, Kirk PC. Nitric oxide and pregnancy. Am J Physiol 1997; 272: 441-63.

[8] Myatt L. Review: reactive oxygen and nitrogen species and functional adaptation of the placenta. Placenta 2010(31): 66-9.

[9] Chwalisz Garfield RE. Role of nitric oxide in implantation and menstruation. Hum Reprod 2000; 15: 96-111.

[10] Yallampalli C, Dong YL, Gangula PR, Fang L. Role and regulation of nitric oxide in the uterus during pregnancy and parturition. J Soc Gynecol Investig 1998; 5(2): 58-67.

[11] Harris LK, McCormick J, Cartwright JE, Whitley GS, Dash PR. S-nitrosylation of proteins at the leading edge of migrating trophoblasts by inducible nitric oxide synthase promotes trophoblast invasion. Exp Cell Res 2008; 314(8): 1765-76.

[12] Jourd'heuil D, Jourd'heuil FL, Kutchukian PS, Musah RA, Wink DA, Grisham MB. Reaction of superoxide and nitric oxide with peroxynitrite. Implications for peroxynitrite-mediated oxidation reactions in vivo. J Biol Chem 2001; 276(31): 28799-805.

[13] Motta AB, Estevez A, Tognetti T, Gimeno MA, Franchi AM. Dual effects of nitric oxide in functional and regressing rat corpus luteum. Mol Hum Reprod 2001; 7(1): 43-7.

[14] Motta AB, Estévez A, Franchi AM, et al. Regulation of lipid peroxidation by nitric oxide and PGF2 alpha during luteal regression in rats. Reproduction 2001; 121: 631-7.

[15] Ogando DG, Paz D, Cella M, Franchi AM. The fundamental role of increased production of nitric oxide in lipopolysaccharide-induced embryonic resorption in mice. Reproduction 2003; 125: 95-110.

[16] Estevez A, Tognetti T, Rearte B, Sander V, Motta AB. Interleukinlbeta in the functional and structural luteolysis. Relationship with the nitric oxide system. Prostaglandins Leukot Essent Fatty Acids 2002; 67(6): 411-7.

[17] Aisemberg J, Vercelli C, Billi S, et al. Nitric oxide mediates prostaglandins' deleterious effect on lipopolysaccharide-triggered murine fetal resorption. Proc Natl Acad Sci USA 2007; 104(18): 75349.

[18] Fatini C, Sticchi E, Gensini F, et al. Endothelial nitric oxide synthase gene influences the risk of pre-eclampsia, the recurrence of negative pregnancy events, and the maternal-fetal flow. J Hypertens 2006; 24(9): 1823-9. 
[19] Purcell TL, Given R, Chwalisz K, Garfield RE. Nitric oxide synthase distribution during implantation in the mouse. Mol Hum Reprod 1999; 5(5): 467-75.

[20] Burnett TG, Hunt JS. Nitric oxide synthase-2 and expression of perforin in uterine NK cells. J Immunol 2000; 164(10): 5245-50.

[21] Yoshino K, Takahashi K, Eda Y, Okada S, Kitao M. Endocrinological environment with regard to the number of microcysts in patients with polycystic ovary syndrome. Hum Reprod 1992; 7(9): 1201-4.

[22] Tagawa N, Hidaka Y, Takano T, Shimaoka Y, Kobayashi Y, Amino N. Serum concentrations of dehydroepiandrosterone and dehydroepiandrosterone sulfate and their relation to cytokine production during and after normal pregnancy. Clin Chim Acta 2004; 340(1-2): 187-93.

[23] Pérez-de-Heredia F, Sánchez J, Priego T, et al. Adiponectin is involved in the protective effect of DHEA against metabolic risk in aged rats. Steroids 2008; 73(11): 1128-36.

[24] Okon MA, Laird SM, Tuckerman EM, Li TC. Serum androgen levels in women who have recurrent miscarriages and their correlation with markers of endometrial function. Fertil Steril 1998; 69(4): 682-90.

[25] Tuckerman EM, Okon MA, Li T, Laird SM. Do androgens have a direct effect on endometrial function? An in vitro study. Fertil Steril 2000; 74(4): 771-9.

[26] Sander V, Solano ME, Gutierrez M, et al. The influence of dehydroepiandrosterone on early pregnancy in mice. Neuroimmunomodulation 2005; 12: 285-92.

[27] Elia E, Vighi S, Lombardi E, Motta AB. Detrimental effects of hyperandrogenism on uterine functions. Int Immunopharmacol 2008; 8(13-14): 1827-34.

[28] Simoncini T, Mannella P, Fornari L, Varone G, Caruso A, Genazzani AR. Dehydroepiandrosterone modulates endothelial nitric oxide synthesis via direct genomic and nongenomic mechanisms. Endocrinology 2003; 144(8): 3449-55.

[29] Eriksson A, Attvall S, Bonnier M, Eriksson JW, Rosander B, Karlsson FA. Short-term effects of metformin in type 2 diabetes. Diabetes Obes Metab 2007; 9(4): 483-9.

[30] Inzucchi SE, Masoudi FA, McGuire DK. Metformin therapy in patients with Type 2 diabetes complicated by heart failure. Am Heart J 2007; 154(6): 45.

[31] Harborne L, Fleming R, Lyall H, Norman J, Sattar N. Descriptive review of the evidence for the use of metformin in polycystic ovary syndrome. Lancet 2003; 361: 1894-1901.

[32] Lord JM, Flight IH, Norman RJ. Insulin-sensitising drugs (metformin, troglitazone, rosiglitazone, pioglitazone, d-chiro-inositol) for polycystic ovary syndrome. Cochr Database Sist Rev 2003; p. 3.

[33] Fenkci V, Fenkci S, Yilmazer M, Sertesser M. Decreased total antioxidant status and increased oxidative stress in women with Polycystic ovary syndrome may contribute to the risk of cardiovascular disease. Fertil Steril 2003; pp. 123-7.

[34] Sena CM, Nunes E, Louro T, Proença T, Seiça RM. Endothelial dysfunction in type 2 diabetes: effect of antioxidants. Rev Port Cardiol 2007; 26(6): 609-19.

[35] Faure P, Rossini E, Wiernsperger N, Richard MJ, Favier A, Halimi $\mathrm{S}$. An insulin sensitizer improves the free radical defense system potential and insulin sensitivity in high fructose-fed rats. Diabetes 1999; 48(2): 353-7.

[36] Srividhya S, Ravichandran MK, Anuradha CV. Metformin attenuates blood lipid peroxidation and potentiates antioxidant defense in high fructose-fed rats. J Biochem Mol Biol Biophys 2002; 6(6): 379-85.

[37] Bonnefont-Rousselot D, Raji B, Walrand S, et al. An intracellular modulation of free radical production could contribute to the beneficial effects of metformin towards oxidative stress. Metabolism 2003; 52(5): 586-9.

[38] Mahrouf M, Ouslimani N, Peynet J, et al. Metformin reduces angiotensin-mediated intracellular production of reactive oxygen species in endothelial cells through the inhibition of protein kinase C. Biochem Pharmacol 2006; 72(2): 176-83.

[39] Faure P, Wiernsperger N, Polge C, Favier A, Halimi S. Impairment of the antioxidant properties of serum albumin in patients with diabetes: protective effects of metformin. Clin Sci (Lond) 2008; 114(3): 251-6.

[40] Formoso G, De Filippis EA, Michetti N, et al. Decreased in vivo oxidative stress and decreased platelet activation following met- formin treatment in newly diagnosed type 2 diabetic subjects. Diabetes Metab Res Rev 2008; 24(3): 231-7.

[41] Zou MH, Kirkpatrick SS, Davis BJ, et al. Activation of the AMPactivated protein kinase by the anti-diabetic drug metformin in vivo. Role of mitochondrial reactive mitogen species. J Biol Chem 2004; 279: 940-51.

[42] Fedorcsak P, Dale PO, Storeng R, Abyholm T, Tanbo T. The effect of metformin on ovarian stimulation and in vitro fertilization in insulin-resistant women with polycystic ovary syndrome: an openlabel randomized cross-over trial. Gynecol Endocrinol 2003; 17: 207-14.

[43] Mansfield R, Galea R, Brincat M, Hole D, Mason H. Metformin has direct effects on human ovarian steroidogenesis. Fertil Steril 2003; 79(4): 956-62.

[44] Mc Carthy EA, Walker SP, Mc Lachlan K, Boyle J, Permezel M. Metformin in obstetric and gynecologic practice: a review. Obstet Gynecol Surv 2004; 59: 118-27.

[45] Nestler JE, Jakubowicz DJ. Decreases in Ovarian Cytochrome $\mathrm{P} 450 \mathrm{c} 17$ alpha activity and serum free testosterone after reduction of insulin secretion in polycystic ovary syndrome. N Engl J Med 1996; 335(9): 617-23.

[46] la Marca A, Egbe TO, Morgante G, Paglia T, Ciani A, De Leo V. Metformin treatment reduces ovarian cytochrome $P-450 \mathrm{c} 17 \mathrm{C}$ response to human chorionic gonadotrophin in women with insulin resistance-related polycystic ovary syndrome. Hum Reprod 2000; 15: 21-3.

[47] Vandermolen DT, Ratts VS, Evans WS, Stovall DW, Kauma SW, Nestler JE. Metformin increases the ovulatory rate and pregnancy rate from clomiphene citrate in patients with polycystic ovary syndrome who are resistant to clomiphene citrate alone. Fertil Steril 2001; 75: 310-5.

[48] Khattab S, Mohsen IA, Foutouh IA, Ramadan A, Moaz M, AlInany H. Metformin reduces abortion in pregnant women with polycystic ovary syndrome. Gynecol Endocrinol 2006; 22: 680-4.

[49] Glueck CJ, Wang P, Goldenberg N, Sieve-Smith L. Pregnancy outcomes among women with polycystic ovary syndrome treated with metformin. Hum Reprod 2002; 17(11): 2858-64.

[50] Glueck CJ, Goldenberg N, Pranikoff J, Loftspring M, Sieve L, Wang P. Height, weight and motor-social development during the first 18 months of life in 126 infants born to 109 mothers with polycystic ovary syndrome who conceived on and continued metformin through pregnancy. Hum Reprod 2004; 19(6): 1323-30.

[51] Solano ME, Elia E, Luchetti CG, et al. Metformin prevents embryonic resorption induced by hyperandrogenisation with dehydroepiandrosterone in mice. Reprod Fertil Dev 2006; 18(5): 533-44.

[52] Luchetti CG, Mikó E, Szekeres-Bartho J, Paz DA, Motta AB. Dehydroepiandrosterone and metformin modulate progesteroneinduced blocking factor (PIBF), cyclooxygenase 2 (COX2) and cytokines in early pregnant mice. J Steroid Biochem Mol Biol 2008; 111(3-5): 200-7.

[53] Guide for the care and use of laboratory animals. Eighth edition. Committee for update of the Guide for the care and use of laboratory animals. Institute for Laboratory Animal Research. National Research Council of the National Academies. The National Academies Press, Washington D.C. 2011.

[54] Ding AH, Nathan CF, Stuehr DJ. Release of reactive nitrogen intermediates and reactive oxygen intermediates from mouse peritoneal macrophages. Comparison of activating cytokines and evidence for independent production. J Immunol 1988; 141(7): 240712.

[55] Misra HP, Fridovich I. The role of superoxide anion in the autoxidation of epinephrine and a simple assay for superoxide dismutase. J Biol Chem 1972; 247(10): 3170-5.

[56] Buege JA, Aust SD. Microsomal lipid peroxidation. Methods Enzymol 1978; 52: 302-10.

[57] Tietze F. Enzymic method for quantitative determination of nanogram amounts of total and oxidized glutathione: applications to mammalian blood and other tissues. Anal Biochem 1969; 27(3): 502-22.

[58] Luchetti CG, Solano ME, Sander V, et al. Effects of dehydroepiandrosterone on ovarian cystogenesis and immune function. J Reprod Immunol 2004; 64(1-2): 59-74.

[59] Motta AB, Estevez A, de Gimeno MF. The involvement of nitric oxide in corpus luteum regression in the rat: feedback mechanism between prostaglandin F (2alpha) and nitric oxide. Mol Hum Reprod 1999; 5(11): 1011-6. 
[60] Sander VA, Piehl L, Facorro GB, Rubín de Celis E, Motta AB. Regulation of functional and regressing stages of corpus luteum development in mice. Role of reactive oxygen species. Reprod Fertil Dev 2008; 20(7): 760-9.

[61] Rengasamy A, Johns RA. Inhibition of nitric oxide synthase by a superoxide generating system. J Pharmacol Exp Ther 1993; 267(3): 1024-7.

[62] Jawerbaum A, Gonzalez E. The role of alterations in arachidonic acid metabolism and nitric oxide homeostasis in rat models of dia- betes during early pregnancy. Curr Pharm Des 2005; 11(10): 132742.

[63] Elia E, Sander V, Luchetti CG, et al. The mechanisms involved in the action of metformin in regulating ovarian function in hyperandrogenized mice. Mol Hum Reprod 2006; 12: 475-81.

[64] Glueck CJ, Wang P, Godenberg N, Sieve-Smith L. Pregnancy outcomes among women with polycystic ovary syndrome treated with metformin. Hum Reprod 2002; 11: 2858-64.

(C) Luchetti et al.; Licensee Bentham Open.

This is an open access article licensed under the terms of the Creative Commons Attribution Non-Commercial License (http://creativecommons.org/licenses/by-nc/3.0/) which permits unrestricted, non-commercial use, distribution and reproduction in any medium, provided the work is properly cited. 